\title{
Pulmonary function, computerized tomography features and six-minute walk test at three months in severe COVID-19 patients treated with intravenous pulsed methylprednisolone: a preliminary report
}

\author{
Cristiano Van Zeller ${ }^{1,2}$, Asad Anwar ${ }^{1,3}$, Nordita Ramos-Bascon'1, Natalie Barnes', Brendan Madden ${ }^{1,3}$ \\ ${ }^{1}$ Department of Cardiothoracic Medicine; ${ }^{2}$ Department of Respiratory Medicine; ${ }^{3}$ Department of Intensive Care, St \\ George's University Hospital, London, UK
}

\begin{abstract}
COVID-19 acute respiratory distress syndrome (ARDS) has a high mortality and few therapeutic options. We present a preliminary report on our experience using high-dose pulsed methylprednisolone in COVID-19 ARDS and three-month outcomes. We performed a retrospective analysis of all patients treated with high-dose methylprednisolone for COVID-19
\end{abstract}

Correspondence: Brendan Madden, Professor of Cardiothoracic and Intensive Care Medicine, St George's University Hospital, London, UK.

E-mail: brendan.madden@stgeorges.nhs.uk.

Authors' contributions: BM designed the study; AA, NRB and NB performed data collection; CVZ conducted the literature review, data analysis, and wrote the manuscript.

Conflict of interest: The authors declare no potential conflict of interest.

Funding: None.

Acknowledgements: The authors would like to thank all the staff in the Lung Function Department at St George's Hospital, especially Qaasim Ismail, and their patients.

Ethical approval: Ethical approval was not required as there was widespread employment of steroid therapy in patients with severe COVID19 worldwide who were at a presumed immunologically driven phase.

Availability of data and materials: All data generated or analyzed during this study are included in this published article.

Key words: COVID-19; ARDS; pulmonary fibrosis; corticosteroids; lung function.

Received for publication: 19 February 2021.

Accepted for publication: 28 April 2021.

${ }^{\circ}$ Copyright: the Author(s), 2021

Licensee PAGEPress, Italy

Monaldi Archives for Chest Disease 2021; 91:1811

doi: 10.4081/monaldi.2021.1811

This article is distributed under the terms of the Creative Commons Attribution Noncommercial License (by-nc 4.0) which permits any noncommercial use, distribution, and reproduction in any medium, provided the original author(s) and source are credited.
ARDS and three-month lung function, 6-minutes walking test (6MWT), and computerized tomography (CT) findings. Fifteen patients were treated of which 10 survived to discharge. Reduced diffusion capacity for carbon monoxide (DLCO) was the commonest abnormality in lung function tests and had the lowest mean value. Parenchymal bands were the commonest CT finding and $50 \%$ of patients had fibrosis at three-months. Mean 6-minutes walk distance $(6 \mathrm{MWD})$ was $65.4 \%$ predicted and was abnormal in $62.5 \%$ of patients. In this cohort of patients with COVID-19 ARDS treated with high-dose methylprednisolone pulses, CT, lung function, and 6MWT abnormalities were unsurprisingly common at three months, although all 10 patients treated early in their disease course survived, a possible therapeutic effect. Further randomised controlled trials are needed to assess the benefits of this treatment.

\section{Introduction}

Coronavirus disease-19 (COVID-19) is the disease caused by infection with SARS-CoV-2 virus. It has had devastating social, economic, and health impacts worldwide. The clinical syndrome of COVID-19 ranges from no or minimal symptoms [1], to respiratory failure and acute respiratory distress syndrome (ARDS) with a high mortality rate [2] especially in those with certain co-morbidities and advancing age [3]. The incidence of pulmonary vascular events is far higher than that seen in other pulmonary infections with comparable severity [4]. Pulmonary thromboses in situ as well as microangiopathy are felt to be occurring in these patients and contributing to the high mortality $[5,6]$. The disease is characterised by an initial viral phase followed by an inflammatory phase where in some patients, severe respiratory failure may develop leading to ARDS [7]. Two drugs have been approved for use in COVID-19 infection in the UK, remdesivir, and corticosteroids, of which dexamethasone is the most commonly used $[8,9]$.

Long-term follow-up of patients with severe acute respiratory syndrome (SARS) and Middle-East respiratory syndrome (MERS) demonstrated that abnormal pulmonary function persists after several years, along with lower 6-minute walk distance (6MWD) and health status scores [10,11]. Several studies have demonstrated an impact of COVID-19 pneumonia on lung function and health status. Abnormalities in lung function after COVID-19 at the time of discharge have been demonstrated in a cohort of 110 patients in China [12] with diffusion capacity for carbon monoxide (DLCO) the commonest followed by total lung capacity (TLC). At 30 days post-discharge Frija-Masson et al. [13] 
assessed lung function in a cohort of 56 patients with COVID-19 pneumonia disease severity ranging from mild to severe, although they did not include patients with ARDS. Their severe disease cohort had normal lung function in only $16 \%$. The prevalence of abnormalities in each parameter is not reported but DLCO was the value demonstrating the lowest median value at $70 \%$ predicted. Huang et al. also followed up patients at 30 days [14]. Of a cohort of 57 patients, including severe and non-severe COVID pneumonia, abnormal DLCO was the most frequent abnormality. In another cohort, at three months DLCO remained the most common abnormality, seen in $16.36 \%$ of patients [15].

Pulsed methylprednisolone was shown to reduce mortality from SARS [16] and in a randomized trial in COVID-19 [17]. Other immune modulators are being studied in the hyperinflammatory stage of COVID-19 with multiple agents in clinical trials [18]. During the first wave of the disease in the UK we observed that the radiological pattern of acute lung injury (ALI) in COVID-19 was similar to an organising pneumonia with non-specific interstitial pneumonia overlap (OP/NSIP overlap), with traction bronchiectasis, extensive ground glass change, and fibrotic change, similar to that seen in connective tissue disease-related interstitial lung disease (CTD-ILD) in which high-dose methylprednisolone is used widely. We hypothesised that this strategy would be of benefit for critically ill patients with COVID-19 who presented with similar radiological features.

Our aim was to assess the radiological, functional, and pulmonary function test outcomes three months after discharge for patients treated for severe COVID-19 ARDS with high-dose methylprednisolone in our intensive care unit (ICU) and present our preliminary findings.

\section{Methods}

We conducted a single centre, retrospective, observational study to evaluate the outcomes at three months post-discharge of all patients treated in our ICU with high-dose methylprednisolone for severe COVID-19 and ARDS. Diagnosis of COVID-19 was made on the basis of either a positive polymerase chain reaction (PCR) test to the SARS-CoV-2 virus, or clinico-radiological features in keeping with COVID-19. The decision on which patients to treat was made by a specific ARDS Support Team put in place during the first wave of COVID-19 infections, between April and May 2020, led by a consultant cardiothoracic intensivist (Professor BM) [19]. Treatment consisted of intravenous methylprednisolone $1 \mathrm{~g}$ once daily for three days $(500 \mathrm{mg}$ for those under $50 \mathrm{~kg}$ in weight) followed by oral prednisolone $40 \mathrm{mg}$ once daily, reducing by $5 \mathrm{mg}$ every three days until a dose of $10 \mathrm{mg}$ once daily. This dose was selected due to the experience in transplant care [20] and in rheumatological conditions [21]. Treatment was considered for patients believed to have an immunologically driven pneumonitis and evolving fibrosis (computed tomography evidence of ground glass shadowing, traction bronchiectasis, fibrotic change) similar to a CTD-ILD, and no evidence for concomitant infection other than COVID-19.

Full lung function tests, unencouraged 6-minute walk test (6MWT), and computed tomography (CT) pulmonary angiography with high-resolution cuts were performed three months after discharge from hospital. Predicted 6MWD was calculated using the Enright equation. CTs done during the inpatient stay were reviewed by a specialist thoracic radiologist to identify classical pulmonary emboli as well as pulmonary thrombosis in situ.
Follow-up CTs were also reviewed by a specialist thoracic radiologist as part of our hospital's COVID follow-up clinic protocol. Lung function testing included spirometry and gas transfer using single breath technique. Ethical approval was not required as there was widespread employment of steroid therapy in patients with severe COVID-19 worldwide who were at a presumed immunologically driven phase. Each patient's treatment was discussed at the time with their next of kin, and subsequently at clinic followup, and was never contested.

Demographic, laboratorial, clinical, and outcome data were retrospectively collected from an electronic patient record. Patients without PCR positivity were deemed to have as a primary diagnosis COVID-19 infection based on the CT changes assessed by the reporting radiologist and the clinical picture assessed by the treating ICU and ARDS Support teams.

\section{Results}

Between the $25^{\text {th }}$ of March and the $26^{\text {th }}$ of June 2020, 15 patients were treated with high-dose methylprednisolone for severe COVID-19 infection in our ICU. Twelve patients had a positive PCR test, whilst three patients never tested positive. Of these, all were diagnosed on the basis of clinico-radiological features, with one patient having positive COVID antibodies at follow-up. According to the severity scale from the National Institutes of Health [22] and World Health Organization [23], 14 patients had critical illness/ARDS and one patient had moderate illness/pneumonia without need for supplemental oxygen, as well as myocarditis in the context of paediatric multisystem inflammatory syndrome (PIMS). Seven patients were transferred from other acute hospitals for extra supportive care. Five patients died in ICU, four from multi-organ failure due to COVID-19 infection and one patient from myocardial infarction. Ten survived to discharge and are still alive. The five patients who died were the first treated in the cohort and received the treatment as a last resort as they showed irreversible deterioration. They were at a far more advanced stage in their disease process than the 10 subsequent patients. One patient required extracorporeal membrane oxygenation (ECMO), for 22 days. Complications of treatment were not common and did not impact on steroid use. One patient developed a subdural haemorrhage two weeks after treatment started and another patient developed an encephalitis seven days after treatment. Steroids were continued in both and they recovered fully without any specific intervention.

Baseline characteristics, co-morbidities, and inpatient outcome data are in Table 1. Twenty percent of patients had no positive COVID swab but had clinical and radiological features consistent with COVID-19 infection. A detailed breakdown of individual patient findings is in the appendix.

Baseline CT thorax on admission to ITU was available in 13 $(86.7 \%)$ patients and all 10 patients who survived to discharge had an admission CT and a follow-up CT (Table 2). Ninety percent of follow-up CTs showed a significant improvement in appearances. One patient had a normal follow-up CT, although the admission CT had only mild ground glass and consolidation as they had mainly presented with PIMS and myocarditis. Parenchymal bands were not present in any admission CT but were the most frequent finding in follow-up imaging. Of the patients diagnosed with a pulmonary embolism (PE) during their inpatient episode, four patients had no residual PE on follow-up imaging and one patient did not survive to discharge. 
Lung function was available in six patients and 6MWT was performed in eight patients on follow-up visits (Table 3). All patients were male as the single surviving female had not completed these tests by the time of submission. One patient was unable to perform either test and one patient moved from our catchment area during the follow-up period and could not complete lung function, however we contacted the patient, and he remains completely asymptomatic, playing football for his higher education institution. Patients with established fibrosis on their CT at three months seemed to have lower lung function.

Table 1. Baseline patient characteristics.

\begin{tabular}{|c|c|}
\hline Characteristic & \\
\hline Age, mean (SD) & 51.1 years $(16.1)$ \\
\hline $\begin{array}{l}\text { Sex } \\
\text { Male } \\
\text { Female }\end{array}$ & $\begin{array}{c}n(\%) \\
13(86.7) \\
2(13.3)\end{array}$ \\
\hline $\begin{array}{l}\text { Race/ethnicity } \\
\text { White } \\
\text { Black } \\
\text { Asian } \\
\text { Mixed }\end{array}$ & $\begin{array}{c}\mathrm{n}(\%) \\
4(26.7) \\
3(20) \\
8(53.3) \\
0(0)\end{array}$ \\
\hline $\begin{array}{l}\text { COVID swab result } \\
\text { Positive } \\
\text { Negative }\end{array}$ & $\begin{array}{l}\mathrm{n}(\%) \\
12(80) \\
3(20)\end{array}$ \\
\hline $\begin{array}{l}\text { Comorbidities* } \\
\text { None } \\
\text { COPD } \\
\text { HTN } \\
\text { Bronchiectasis } \\
\text { Type } 2 \text { diabetes } \\
\text { HIV } \\
\text { Asthma } \\
\text { Lymphoma } \\
\text { Renal transplant } \\
\text { Hepatitis B virus infection } \\
\text { Epilepsy } \\
\text { Atrial fibrillation }\end{array}$ & $\begin{array}{l}\mathrm{n}(\%) \\
6(40) \\
1(6.7) \\
1(6.7) \\
1(6.7) \\
1(6.7) \\
1(6.7) \\
1(6.7) \\
1(6.7) \\
1(6.7) \\
1(6.7) \\
1(6.7) \\
1(6.7)\end{array}$ \\
\hline $\begin{array}{l}\text { Respiratory support } \\
\text { Low-flow nasal oxygen } \\
\text { IMV } \\
\text { ECMO }\end{array}$ & $\begin{array}{c}n(\%) \\
1(6.7) \\
13(86.7) \\
1(6.7)\end{array}$ \\
\hline $\begin{array}{l}\text { Complications }{ }^{\#} \\
\text { Sepsis } \\
\text { Acute kidney injury } \\
\text { Cardiac arrest } \\
\text { Subdural bleed } \\
\text { Myocardial infarction } \\
\text { Cardiac dysrhythmia } \\
\text { Encephalitis } \\
\text { Acute liver failure } \\
\text { Elevated liver enzymes } \\
\text { Coagulopathy }\end{array}$ & $\begin{array}{c}\mathrm{n}(\%) \\
9(60) \\
8(53.3) \\
1(6.7) \\
1(6.7) \\
1(6.7) \\
2(13.3) \\
1(6.7) \\
1(6.7) \\
1(6.7) \\
2(13.3)\end{array}$ \\
\hline $\begin{array}{l}\text { Length of stay, mean, (days) } \\
\text { Intensive Care Unit } \\
\text { Total LOS }\end{array}$ & $\begin{array}{l}29.3 \\
46.5\end{array}$ \\
\hline
\end{tabular}

*Percentages may add up to more than 100 as patients may have had more than 1 co-morbidity; ${ }^{\circledR}$ other than the complications mentioned in the text, all complications occurred during inpatient stay prior to methylprednisolone treatment; ${ }^{\circ}$ length of stay (LOS) includes inpatient stay before transfer to our institution, and after stepdown to a general medical ward; COPD, chronic obstructive pulmonary disease; HTN, hypertension; HIV, human immunodeficiency virus; IMV, intermittent mandatory ventilation; ECMO, extra-corporeal membrane oxygenation.

\section{Discussion}

We present our cohort of 15 patients with severe COVID-19 infection treated with high-dose intravenous methylprednisolone. Fourteen of the 15 patients required invasive mechanical ventilation (IMV) due to type one respiratory failure, for a mean of 16.4 days.

At three months post discharge $90 \%$ of patients in our cohort had persistent CT changes. Similar to Liu et al. [24], parenchymal bands and ground glass opacity were the most frequent persistent change although this study ended follow-up at four weeks. One study looked at radiological abnormalities of 55 COVID-19 patients three months after discharge and reported abnormalities in $70 \%$ of patients [16]. This is slightly lower than the $90 \%$ in our cohort and might partly be explained by our higher proportion of critical disease: whereas in that study only four out of 55 patients had severe disease, 14 out of 15 in our cohort had. As was the case with other severe respiratory viral infections, such as avian influenza [25], radiological changes seem to persist for several months after infection with SARS-CoV-2.

There was also a high incidence of abnormal lung function tests in our cohort, higher than in most other published cohorts, similarly likely due to disease severity. Of note, none of the patients had known pre-existing lung disease. The most frequent abnormality seen was a reduced DLCO, present in five out of six $(83 \%)$ patients, much higher than in other studies [15], with a median value inferior to that seen in other studies [14]. This was seen even in patients without established fibrosis radiologically, suggesting either microscopic change in the lung parenchyma, or microangiopathic disease observed in post-mortem studies [26]. Most patients had normal gas transfer when corrected for alveolar volume. This could be due to respiratory muscle weakness developed as a consequence of prolonged ventilation or a distinct clinical entity associated with COVID-19 which has been demonstrated at 30 days post discharge [15] although we did not formally test for respiratory muscle strength. As expected, patients with established fibrosis seemed to have worse gas transfer and forced vital capacity (FVC) than those without (Table 4). The patient that did not have lung function done mainly had PIMS with myocarditis and some lung involvement on CT. Since being discharged, they have begun higher education studies and are actively playing in the institution's football team without any limitations suggesting little to no impact on lung function.

Most patients had a 6MWD lower than predicted, and the mean for the whole cohort was lower than predicted, with the lowest value at $31 \%$ in a patient who developed severe critical illness neuromyopathy. A multitude of factors are likely to be contributing to this, including reduced lung function, deconditioning from prolonged intubation, critical illness neuropathy and myopathy, and potentially undiagnosed long COVID in our cohort. In fibrotic patients there was significant desaturation at the end of the test despite the short distances walked, reinforcing the notion that there are ongoing parenchymal and microangiopathic changes causing significant lung impairment.

Our study had several limitations. We report data from a single centre however we received patients from several other hospitals in London, as our institution has one of the biggest ICU capacities in the region. There was no control group and it is retrospective in nature although, at the outset of the pandemic, it was felt to not be ethical to withhold a treatment with potential 
clinical benefits to these patients presenting with severe disease. There were several missing data points mainly due to patients not attending appointments, and the number of patients was small. Finally, two of the ten surviving patients never tested positive on a PCR for the SARS-CoV-2 virus, although one patient subsequently tested positive for COVID-19 antibodies on fol-

Table 2. Computed tomography (CT) findings during inpatient stay and at three-month follow-up.

\begin{tabular}{|c|c|c|c|}
\hline CT feature & $\begin{array}{c}\text { Inpatient CT } \\
\text { (all patients), } \\
\text { n (\%) }\end{array}$ & $\begin{array}{c}\text { Inpatient CT } \\
\text { (survived to discharge; } \mathrm{n}=10 \text { ), } \\
\mathrm{n}(\%)\end{array}$ & $\begin{array}{l}\text { Follow-up CT } \\
\begin{array}{c}(n=10) \\
n(\%)\end{array}\end{array}$ \\
\hline Normal & $0(0)$ & 0 & $1(10)$ \\
\hline Consolidation & $12(80)$ & $8(80)$ & $2(20)$ \\
\hline Ground glass & $13(86.7)$ & $9(90)$ & $6(60)$ \\
\hline Traction bronchiectasis & $4(26.7)$ & $3(30)$ & $6(60)$ \\
\hline Pneumomediastinum & $1(6.7)$ & $1(10)$ & $0(0)$ \\
\hline Pulmonary embolism & $5(33.3)$ & $4(40)$ & $0(0)$ \\
\hline Fibrosis & $1(16.7)$ & $1(10)$ & $5(50)$ \\
\hline Pleural effusion & $5(33.3)$ & $2(20)$ & $0(0)$ \\
\hline Parenchymal bands & $0(0)$ & $0(0)$ & $7(70)$ \\
\hline
\end{tabular}

Table 3. Pulmonary function test (PFT) and 6-minutes walk test (6MWT) results at three months.

\begin{tabular}{|c|c|c|}
\hline Pulmonary function tests* & Whole cohort $(n=6)$ & Patients with established fibrosis $(\mathrm{n}=3$ ) \\
\hline $\mathrm{FEV}_{1}$ (Litres) & $3(0.85)$ & $2.56(1.4)$ \\
\hline $\mathrm{FEV}_{1}(\%$ predicted $)$ & $85.6(17.6)$ & $77.2(42.6)$ \\
\hline FVC (Litres) & $3.59(1.2)$ & $3.01(0.7)$ \\
\hline FVC (\% predicted) & $79.3(18.1)$ & $71.4(19.5)$ \\
\hline $\mathrm{FEV}_{1} / \mathrm{FVC}$ & $0.80(0.04)$ & $0.81(0.02)$ \\
\hline DLCO, mean \% predicted & $58(15.4)$ & $48(11)$ \\
\hline $\mathrm{KCO}$, mean \% predicted & $91(17.1)$ & $86(19.1)$ \\
\hline TLC\# (mean), \% predicted & $67(17.9)$ & $60(12.6)$ \\
\hline 6 -minute walk test ${ }^{\circ}$ & Whole cohort $(\mathrm{n}=8)$ & Patients with established fibrosis $(\mathrm{n}=3$ ) \\
\hline Distance (metres) & $405(87.5)$ & $350.6(104.5)$ \\
\hline Distance (\% predicted) & $65.4(18.5)$ & $48.2(23.1)$ \\
\hline Pre-test BORG score & $1(1)$ & $1.25(1.2)$ \\
\hline Post-test BORG score & $2.5(2)$ & $3.5(3.1)$ \\
\hline Pre-test $\mathrm{O}_{2}$ saturation (\%) & $97.5(1)$ & $97.3(1.3)$ \\
\hline Post-test $\mathrm{O}_{2}$ saturation (\%) & $94.25(4.5)$ & $91.8(5.4)$ \\
\hline
\end{tabular}

Table 4. Frequency of lung function and 6-minutes walk distance (6MWD) abnormalities (n=6 patients who had lung function at threemonth follow up).

Lung function parameter in (\% total)

\begin{tabular}{lc} 
FEV1 & $1(16.7)$ \\
FVC & $3(50)$ \\
\hline FEV $/$ FVC & $0(0)$ \\
DLCO & $5(83.3)$ \\
\hline KCO & $1(16.7)$ \\
TLC & $5(83.3)$ \\
Normal lung function & $1(16.7)$ \\
6MWD & $5(62.5)$ \\
\hline
\end{tabular}

6MWD, 6-minute walk distance; DLCO, diffusion capacity for carbon monoxide; $\mathrm{FEV}_{1}$, forced expiratory volume in 1 second; FVC, forced vital capacity; KCO, carbon monoxide transfer coefficient; TLC, total lung capacity. 
low-up. This is partly explained by the uncertainty at the outset of the pandemic as to the optimal site for sampling for the virus, leading to many false negative swabs. However, they demonstrated typical clinico-radiological features in keeping with severe COVID-19 throughout their disease course.

Corticosteroids have been shown to improve outcomes in patients with COVID-19 pneumonia, suggesting they modulate the dysregulated immune process [27]. In the only published randomized controlled trial of pulsed methylprednisolone therapy there was a survival benefit [18]. Other non-randomized retrospective studies also suggest a survival benefit and reduction in need for intubation, although patients had less severe disease than in our cohort $[28,29,30]$. The 10 patients who survived all had a radiological appearance similar to that seen in CTD-ILDs and we felt that aggressive treatment could improve their outcome, based on the experience of treatment of those CTD-ILDs and in transplant patients. Our cohort consisted only of extremely unwell patients, in which 14 out of 15 were mechanically ventilated when treated, and for a total mean of 16.4 days, with one patient needing ECMO for 22 days. Methylprednisolone was used in those for whom treatment options were extremely limited and prognosis was very poor and therefore, perhaps unsurprisingly, the frequency of physiological and radiological abnormalities at three months was very high. However, we feel that were we not to have used this treatment some of these patients would not have survived and, those who would have, potentially would have had even more severe impairments than were observed, although our study cannot establish causality between the treatment and this observation. The five patients who died were treated as a last-ditch attempt and the prognosis was extremely poor by that stage whereas the following 10 were treated earlier in their disease course.

Despite the limitations of our trial, we feel it raises the possibility that intervention with high-dose methylprednisolone in patients with severe COVID-19, and ARDS, might improve outcomes. This inflammatory process could be patho-physiologically and radiologically, similar to that seen in CTD-ILDs, and the use of high dose methylprednisolone at the early stages of the fibrotic process may aggressively intervene in the it, improving both pulmonary thrombosis in situ and interstitial fibrosis. Criteria to identify the optimal timing for administration of this treatment and identification of the clinico-radiological features of patients most likely to benefit are necessary and will allow more widespread adoption. Only further large good quality randomised control trials could answer this question.

\section{Conclusions}

In our cohort of patients with severe COVID-19 and ARDS treated with high-dose methylprednisolone at three months postdischarge, lung function, CT, and 6MWT abnormalities were expectedly common. When used in patients at early stages of their disease process all of them survived, although mortality benefits cannot be inferred from this study. However, it might have improved the outcome in these severely unwell patients. Randomized controlled trials to assess the acute and long-term impact of this treatment would be beneficial.

\section{References}

1. Vetter P, Lan Vu D, L'Hullier AG, et al. Clinical features of COVID-19. BMJ 2020;369:m1470.

2. Grasselli G, Tonetti T, Protti A, et al. Pathophysiology of COVID-19- associated acute respiratory distress syndrome: a multi-center prospective observational study. Lancet Respir Med 2020;8:1201-8.

3. Jordan RE, Adab P, Cheng KK. COVID-19: risk factors for severe disease and death. BMJ 2020;368:m1198.

4. Bompard F, Monnier H, Saab I, et al. Pulmonary embolism in patients with COVID-19 pneumonia. Eur Respir J 2020;56:2001365.

5. Wang L, Chen F, Bai L, et al. In situ pulmonary thrombosis in patients with COVID-19 pneumonia: different phenotypes may exist. Thromb Res 2020;196:S41-2.

6. McGonagle D, O'Donnel JS, Sharif K, et al. Immune mechanisms of pulmonary intravascular coagulopathy in COVID-19 pneumonia. Lancet Rheumatol 2020;2:e437-45.

7. Tay MZ, Poh CM, Renia L, et al. The trinity of COVID-19: immunity, inflammation and intervention. Nat Rev Immunol 2020;20:363-74.

8 UK Government. Selected NHS patients to access Coronavirus treatment remdesivir. Accessed: 11/10/2020. Available from: https:/www.gov.uk/government/news/selected-nhs-patientsto-accesscoronavirus-treatment-remdesivir

9. UK Government. World first coronavirus treatment approved for NHS use by Government. Accessed: 11/10/2020. Available from: https://www.gov.uk/government/news/world-first-coronavirus-treatmentapproved-for-nhs-use-by-government

10. Ngai JC, Ko FW, Ng SS, et al. The long-term impact of severe acute respiratory syndrome on pulmonary function, exercise capacity and health status. Respirology 2010;15:543-50.

11. Ahmed H, Patel K, Greenwood DC, et al. Long-term clinical outcomes in survivors of severe acute respiratory syndrome and Middle East respiratory syndrome coronavirus outbreaks after hospitalization and ICU admission: a systematic review and meta-analysis. J Rehabil Med 2020;52:jrm00063.

12. Mo X, Jian W, Su Z, et al. Abnormal pulmonary function in COVID-19 patients at time of hospital discharge. Eur Respir J 2020;55:2001217.

13 Frija-Masson J, Debray M-P, Gilbert M, et al. Functional characteristics of patients with SARS-CoV-2 pneumonia at 30 days post-infection. Eur Respir J 2020;56:2001754.

14. Huang Y, Tan G, Wu J, et al. Impact of Coronavirus 2019 disease on pulmonary function in early convalescence phase. Respir Res 2020;21:163.

15. Zhao Y-M, Shang Y-M, Song W-B, et al. Follow-up study of the pulmonary function and related physiological characteristics of COVID-19 survivors three months after recovery. EClinicalMedicine 2020;25:100463.

16. Yam L Y-C, Lau A C-W, Lai F Y-L, et al. Corticosteroid treatment of severe acute respiratory syndrome in Hong Kong. J Infect 2007;57:28-39.

17. Edalatifard M, Akhtari M, Salehi M, et al. Intravenous methylprednisolone pulse as a treatment for hospitalised severe COVID-19 patients: results from a randomized control trial. Eur Respir J 2020;56:2002808.

18. The Pharmaceutical Journal. Everything you need to know about the COVID-19 therapy trials. Royal Pharmaceutical Society. Accessed: 2/12/2020. Available from: https://www. pharmaceutical-journal.com/news-andanalysis/features/every- 
thing-you-need-to-know-about-the-covid-19-therapytrials/ 20208126.article?firstPass $=$ false

19. Asad A, Ramos-Bascon N, Barnes N, Madden B. A specialized cardiorespiratory team approach in the intensive care management of COVID-19 patients: benefit on mortality, diagnosis and management. Clin Med (Lond) 2021;21:101-6.

20. Madden BM, Hodson ME, Tsang V, et al. Intermediate-term results of heart-lung transplantation for cystic fibrosis. Lancet 1992;339:1583-7.

21. Vij R, Strek ME. Diagnosis and treatment of connective tissue disease associated interstitial lung disease. Chest 2013;143: 814-24.

22. National Institutes of Health. Clinical presentation of people with SARS-CoV-2 infection. Accessed: 2/12/2020. Available from: https:/www.covid19treatmentguidelines.nih.gov/ overview/clinical-presentation

23. World Health Organization. Clinical Management of severe respiratory infection (SRI) when COVID-19 disease is suspected. Accessed: 2/12/2020. Available from: https://apps.who. int/iris/bitstream/handle/10665/331446/WHO-2019-nCoVclinical-2020.4-eng.pdf?sequence $=1 \&$ isAllowed $=y$

24. Liu D, Zhang W, Pan F, et al. The pulmonary sequelae in discharged patients with COVID-19: a short-term observational study. Respir Res 2020;21:125.
25. Wang Q, Jiang H, Xie Y, et al. Long-term clinical prognosis of human infections with avian influenza A (H7N9) viruses in China after hospitalization. EClinicalMedicine 2020;20: 100282.

26. Hanley B, Naresh KN, Roufosse C, et al. Histopathological findings and viral tropism in UK patients with severe fatal COVID-19: a post-mortem study. Lancet Microbe 2020;1: e245-53.

27. RECOVERY Collaborative Group, Horby P, Lim WS, et al. Dexamethasone in hospitalized patients with COVID-19 Preliminary report. N Engl J Med 2021;384:693-704.

28. Fernandez-Cruz A, Ruiz-Antorán B, Muñoz-Gómez A, et al. A retrospective controlled cohort study of the impact of glucocorticoid treatment in SARSCoV-2 infection mortality. Antimicrob Agents Chemother 64:e01168-20.

29. Cellajs Rubio JL, Luna del Castillo JD, de la Hera Fernandéz $\mathrm{J}$, et al. Effectiveness of corticoid pulses in patient with cytokine storm syndrome induced by SARS-CoV-2 infection. Med Clin (Barc) 2020;155:159-61.

30. So C, Ro S, Murakami M, et al. High-dose, short-term corticosteroids for ARDS caused by COVID-19: a case series. Respirol Case Rep 2020;8:e00596. 